\title{
Economia Política da Informação, da Comunicação e da Cultura: dimensões cruzadas entre ética e epistemologia: entrevista ${ }^{1}$ com Graham Murdock ${ }^{2}$
}

\author{
Political Economy of Information, Communication and Cultures \\ ethical and epistemological crossed dimensions: an interview with \\ Graham Murdock
}

\author{
Graham Murdock* \\ Marco Schneider ${ }^{* *}$
}

1 - Conte-nos um pouco sobre o seu trabalho, considerando os fundamentos epistemológicos da economia política da informação, comunicação e cultura.

Meu trabalho se baseia em uma versão do realismo crítico, com o objetivo de combinar o estudo dos processos estruturais profundos que organizam a vida com as consequências para a prática e imaginação cotidianas. Busco colocar esses dois níveis de análise no mesmo espaço, evitar separar de um lado uma abordagem abstrata e de outro uma concreta, mas alcançar a síntese dialética entre processo estrutural e ação situada - e, claro, essa ação individual também significa ação coletiva. Este é de fato o problema central na sociologia, a relação entre estrutura e ação, como atingir esses dois níveis de análise na mesma abordagem. Considero algumas perspectivas na economia política abstratas demais, muito "meta", enquanto alguns estudos culturais se fundamentam demais na vida cotidiana. O livro que me instigou a virar cientista social quando era adolescente foi "A Imaginação Sociológica", do Charles Wright Mills. Segundo ele, é nossa obrigação mover entre o abstrato e o particular, para então encontrar a relação entre eles. Ainda hoje essa poderia ser a ambição central do meu trabalho.

2- Quais conexões você apontaria entre a economia política da informação, comunicação e cultura com o marxismo e com escolas de pensamento econômico consideradas heterodoxas?

A ideia de escola heterodoxa está de novo em voga mas é uma categoria muito elástica, pode se referir a qualquer forma de pensamento econômico fora o

\footnotetext{
${ }^{1}$ Entrevista realizada em 2015 e revista pelo autor em 2020

${ }^{2}$ Tradução de Monique Figueira

* Loughborough University, Social Sciences Department, Faculty Member.

** Doutor em Comunicação pela Universidade de São Paulo. Pesquisador do lbict . Professor do Programa de Pós-Graduação em Ciência da Informação - PPGCl-Ibict/UFRJ e do Programa de PósGraduação em Mídia e Cotidiano - Universidade Federal Fluminense (PPGMC-UFF). Endereço: Rua Lauro Muller, 455 - $4^{\circ}$ andar - 22290-160 - Rio de Janeiro - RJ. Telefone: (21) 2275-0321. E-mail: marcoschneider@ibict.br.
} 
liberalismo clássico, então não considero útil. Além disso, nem todas as tradições heterodoxas são críticas. O ponto principal em Marx foi partir da organização da produção, não onde parece estar a troca - creio que esse segue sendo o ponto de partida mais importante, a produção da vida cotidiana. A partir daí tem se travado um longo debate sobre a relação entre mercados e Estados. Essa preocupação é central particularmente na Europa porque temos uma tradição de investimento público na cultura, na comunicação e na radiodifusão. Então discute-se como equilibrar a dinâmica do mercado com subsídio público, regulação e organização estatal, a considerar ainda como o sistema cultural está organizado e impulsiona esses eixos. A indústria cinematográfica, por exemplo, sempre foi comercial, mas para nós há muito tempo a radiodifusão é primordialmente um serviço público. Então a pergunta é como organizar essa relação: o que pertence ao mercado e o que pertence ao setor público? Recentemente tenho me interessado pela atividade na internet, então eu gostaria de adicionar um terceiro domínio a este debate, que é a ideia de economia colaborativa, onde as pessoas se unem para criar coletivamente algo fora do mercado, mas também fora do sistema público estatal. A Wikipédia seria o exemplo mais conhecido, mas há várias iniciativas de pessoas trabalhando juntas, doando seu tempo e experiência para criar algo que será disponibilizado de modo aberto e gratuito a todos, mas de modo auto-organizado. Então agora temos três tipos de domínio econômico: o mundo das mercadorias, o mundo dos bens públicos estatais e também essa nova economia recíproca colaborativa, então eu tenho me interessado na relação entre eles. Sem dúvidas a economia de commodities segue tentando invadir cada espaço disponível e expulsar os demais, mas também há um contramovimento forte e bem esperançoso. A internet tem forçado os economistas políticos a irem além do dualismo entre Estado e mercado, a fim de dar conta deste terceiro conjunto, o que abre possiblidades interessantes de análise.

\section{3 - Quais conexões você apontaria entre a economia política da informação, comunicação e cultura com a comunicação social, a ciência da informação e os estudos culturais?}

Eu não faço essas divisões. As universidades fazem tais distinções quando querem construir impérios de departamentos. Não considero útil, penso mais em níveis de análise. Trabalhei muito com estudos culturais, que se propõem majoritariamente a estudar a vida simbólica como uma variedade de artefatos e práticas, enquanto podemos dizer que a economia política está mais para a produção das condições de ação. Para mim ambos são absolutamente necessários e de modo algum antagônicos, mas apenas níveis diferentes de análise, depende da pergunta que se quer responder. Se você quer o significado da televisão na vida das pessoas, então você não precisa de economia política. Se você quer responder por que temos a televisão que temos, aí, sim, você precisa de economia política. Sempre me frustrei com esse argumento que haveria algum tipo de antagonismo ou divisão. Então ciência da informação não me parece uma combinação útil de ideias porque foca muito numa categoria específica da comunicação, enquanto a comunicação na verdade é um sistema plural e integrado, então há de se dar conta da comunicação visual, da comunicação oral, e por aí vai. Não vejo como essas divisões poderiam ajudar. Estamos interessados nos modos que as pessoas se relacionam umas com as outras, como usam meios simbólicos para tanto e como essa prática está estruturada em processos fundamentais de poder e desigualdade. Então para mim tudo isso faz parte da mesma questão. 


\section{4 - Há algum compromisso ético no campo da economia política da informação, comunicação e cultura?}

Sim, a filosofia moral foi absolutamente central para o projeto original da economia política. Adam Smith foi professor de filosofia moral na Universidade de Glasgow e apesar de eu discordar da análise, o projeto dele estava correto porque o ponto principal de investigação partiu da pergunta mais importante: o que é uma boa sociedade? Em primeiro lugar, que valores queremos promover? Em segundo lugar, como encorajar em termos de práticas institucionais? Como sustentar esses valores? Ainda sou um filho do lluminismo, então acho que nosso principal problema ainda remonta à Revolução Francesa, onde você tem três princípios, liberdade, igualdade e solidariedade. A pergunta é: como se organiza a relação entre eles? Os três princípios são necessários, mas a sociedade civil organizada tende a valorizar demais a liberdade individual, em detrimento da responsabilidade social, ou, em menor escala, o oposto. Ainda estamos lutando contra esse antigo problema filosófico, como reconciliar esses princípios. Então a economia política é parte da tentativa de responder aquela pergunta sobre a boa sociedade. Por exemplo, as pessoas perguntam por que defender um tipo particular de radiodifusão. Não é por ser mais eficiente ou lucrativo, mas porque estimula um campo cultural que apoia esses valores, particularmente $o$ da reciprocidade, generosidade e da sociabilidade social, em oposição a um individualismo tacanho. Vivemos um mundo de momentos individualizados e as novas tecnologias da comunicação são parte do problema. Elas nos encorajam a ser mais fechados, em vez de abertos. Para mim não é só um problema prático, é um problema filosófico. Eu apoio uma sociedade mais aberta, mais generosa, mais respeitosa, mais cosmopolita. Então para mim a comunicação deve ser julgada em termos do quanto encoraja esses tipos de disposições. Questões técnicas não são as mais importantes. As perguntas mais importantes são como vivemos uns com os outros e como usamos a comunicação para encorajar um modo mais generoso e aberto de estar juntos, menos destrutivo, menos violento, menos preconceituoso. Então para mim é inevitável, você não pode falar de comunicação sem abordar a conexão social. É sobre as relações que temos uns com os outros, o modo como sustentamos esses relacionamentos, então talvez possamos escolher estudar todas essas questões. De qualquer modo, pra mim comunicação é uma área onde as questões éticas são centrais.

\section{5 - Há alguma legitimidade científica ou arcabouço racional que apoie esse compromisso ético?}

Novamente, remetemos a essa questão fundamental da relação entre investigação e julgamento. Eu não tenho uma resposta final para isso, mas vou buscar ser o mais rigoroso possível. Não sei se "científica" é a maneira mais adequada para descrevê-la, mas ao desenvolver uma análise, você procura ser abrangente e explicar o máximo possível do material empírico que tem disponível, de modo elegante e convincente. Bourdieu disse algo muito interessante sobre pesquisa social. Segundo ele, pesquisas são boas para gerar perguntas. Creio que um dos frutos mais produtivos de uma análise é levantar novos tipos de perguntas e rearranjar o campo intelectual para que gere um novo conjunto de problemas, em um processo sem fim. Sim, é necessário ter uma análise rigorosa, mas isso não basta. Se, por exemplo, você elaborasse uma análise rigorosa sobre o fascismo e entendesse suas raízes, você não poderia parar aqui. Não se pode só dizer "aqui está a análise, espero que interesse" porque o fascismo é algo que você também tem que se opor. Então penso que é inevitável ser tanto um analista quanto um ator ético. Você também é cidadão, também 
protagonista nessas lutas. Então eu nunca aceitei essa ideia de que seja possível separar essas posturas, que o trabalho de alguém seria apenas focar na sua própria análise e deixar a responsabilidade de agir para os outros. Precisamos ter, como se diz em inglês, a coragem de nossas convicções, segui-las através da forma de intervenção que lhe for mais apropriada. É interessante que, mais para o final de sua vida, Bourdieu se revoltava cada vez mais com o que estava acontecendo na França, foi se tornando cada vez mais protagonista assim como analista social. Acho isso inevitável ao se deparar com desigualdades colossais, por exemplo, não acho possível escrever um livro sobre desigualdade e não fazer nada quanto a isso. Na verdade, seria até imoral. O foco da análise é dramatizar o problema, mostrar o quão destrutivo é para o potencial humano. Essa é uma conclusão analítica e também um convite ético.

Schneider - Também estético, como esta entrevista. Aqui em Cuba, uma direção a la Godard para o nosso filme por vir...

Murdock - Sim, isso... [risos]

\section{6 - Que bibliografias você sugere para a economia política da informação, comunicação e cultura?}

Essa é difícil. Venho de uma educação heterodoxa, então confesso que em geral acho mais proveitosas certas obras de cientistas fora da área de comunicação. Na minha opinião o livro do Thomas Piketty, O Capital no Século XXI, faz uma intervenção fundamental, é uma leitura de referência para a economia política nas últimas décadas. Não fala nada sobre comunicação em si mas acho que todos deveriam ler. $\mathrm{O}$ livro trata das condições históricas sob as quais todos vivemos e porque são deste modo. Piketty recentemente publicou um segundo volume, "Capital e ideologia", projeto ainda mais ambicioso que aborda a escravidão e o colonialismo em paralelo ao capitalismo. Todo seu trabalho está centrado na organização da desigualdade, sua reprodução e quais políticas poderiam combatê-la. Então pra mim livros importantes enquadram a conjuntura e te forçam a perguntar novas questões.

Por isso acho que Bourdieu foi tão produtivo, porque ele usou toda metodologia que há disponível. As pessoas em geral lembram mais de "A distinção", mas "A Miséria do mundo" fica o tempo todo testando modos diferentes de entender o mundo e acessar a vida das pessoas. Foi um projeto temporário fantástico que Bourdieu acabou não terminando, porque ele não parava nunca. Tenho grande admiração por pessoas que não são só sofisticadas teoricamente, mas também ativas em tentar desvendar o que realmente está acontecendo com o mundo.

Há anos escrevi com colegas um livro bem conhecido sobre metodologia intitulado "Researching Communications: A Practical Guide to Methods in Media and Cultural Analysis" - aliás, em 2020 publicaremos a terceira edição atualizada. Esse livro pode ser considerado um clássico, mas para nós foi uma descoberta por duas razões: em primeiro lugar, foi genuinamente um projeto colaborativo, nós vínhamos de diferentes expertises e aprendemos muito com os outros. Em segundo lugar, o livro faz uma combinação incomum entre ciências sociais e humanidades - abordando assuntos desde estatística até análise de discurso - e defende que ambos são necessários para uma compreensão abrangente da comunicação como multidimensional.

Além desses, nos últimos anos tenho me envolvido com questões ambientais. Meu último livro foi editado com Bene Brevini e se chama "Communication and Carbon 
Capitalism: Confronting Climate Crisis", então hoje enfatizo mais a urgência de colocar a crise climática no centro da economia política crítica. Para citar um livro como ponto de partida nessa temática, recomendo o "Dougnut Economics" da Kate Raworth, que associa a defesa do meio-ambiente com as preocupações tradicionais da economia política crítica, como igualdade e justiça social.

Enfim, investigar é tão importante quanto teorizar, ambos são de fato interdependentes. Sem um projeto de descortinamento da realidade não se atinge uma boa teoria, você só juntou uma confusão de palavras. Infelizmente hoje em dia há muitas dessas teorias sem base real no que está acontecendo no mundo. Então os autores que recomendo estão comprometidos com a reflexão teórica mas também com a descoberta. Acho que Piketty e Bourdieu estão entre os principais autores. Não que seja necessário concordar com eles, não é sobre estar certo mas sobre o projeto, cada um pode segui-lo de seu próprio modo e questioná-lo. Ambos pensadores tem sido tão fundamentais, só te resta interagir, observar e considerar certas questões. Então todos os grandes nomes, como Marx e Freud, são pensadores que você não pode evitar, há de se passar por eles. Você pode até não absorver muito, mas tem que se confrontar com seriedade porque eles levantam questões fundamentais que todos nós precisamos ter opinião sobre. Então recomendo esses escritores porque eles são um desafio, uma provocação. Se uma escrita não provoca ela não é interessante pra mim. [risos]

\section{7 - Também vejo essa complementaridade entre os estudos culturais e a economia política da comunicação, as áreas quando surgiram estavam mais próximas. Por outro lado, desde os anos setenta os estudos culturais abandonaram o marxismo, mas a economia política não. Concorda?}

É complicado porque há várias direções em países diferentes. Os estudos culturais nos Estados Unidos são muito diferentes do que se desenvolveu no Reino Unido. Posso falar do Reino Unido, apesar de nunca ter sido membro do Centro de Estudos Culturais de Birmingham, mas eu ia com frequência aos congressos. O "Resistance Through Ritual" segue como uma das principais obras do instituto, onde contribuí com um capítulo sobre a juventude. Eu era próximo ao Stuart Hall, nunca houve qualquer questão entre nós. Ele tinha interesses diferentes mas conseguíamos conversar, o que nos unia era a política, tínhamos a mesma orientação e muitos interesses teóricos em comum. Isso é verdade para vários dos primeiros pesquisadores que estavam desenvolvendo os estudos culturais ali, muitos formados em sociologia, por exemplo, mas penso que novamente voltamos a essa ideia de construção de impérios. Os estudos culturais encontraram sua casa institucional primordialmente nas faculdades de literatura e ali se assentaram, nunca pertenceram ao departamento de ciências sociais. Então o campo foi atraído em direção a análise de conteúdo, estudo de audiência e por aí vai, estavam pouco interessados na questão da produção. Creio que foi quando as coisas começaram a se dividir, pois a economia política sempre se ocupou da produção da cultura no coração do sistema e dos grandes atores. Penso que foi um tipo de divisão institucional, a maioria dos pesquisadores na economia política se consideravam cientistas sociais de algum tipo, enquanto muitos protagonistas nos estudos culturais estavam na literatura, análise de discurso e talvez linguística. Não seria problemático se as pessoas aceitassem isso

\footnotetext{
${ }^{3}$ Resistance Through Rituals: Youth Subcultures in Post-War Britain, edited by Stuart Hall and Tony Jefferson (2006).
} 
como divisão do trabalho, algo importante porque ninguém consegue dar conta de tudo. Mas se tornou antagonismo, houve competição por recursos, por alunos, e vejo isso como um problema institucional, não analítico. Analiticamente claro que todas essas abordagens são necessárias para entender como a comunicação funciona, pois dizem respeito a momentos diferentes no processo, mas infelizmente as universidades na prática são contra a interdisciplinaridade. As instituições acadêmicas se dividiram em departamentos imperiais que defendem suas fronteiras contra os forasteiros, então o departamento de economia não dialoga com o departamento de sociologia ou ciência política. Acho que isso aconteceu com os estudos culturais e fez sucesso com os estudantes. Foram inaugurados departamentos de estudos culturais, diplomas em estudos culturais, fundados para se defender no âmbito institucional, porque as universidades são muito tradicionais, não confiam muito em novas áreas de atuação. $O$ campo tinha que reivindicar sua singularidade para se afirmar perante os titulares da instituição e seus recursos. Contudo, essa reivindicação se torna mais que estratégica, pois muitas pessoas passaram a acreditar que os estudos culturais são algo muito especial e diferente. Pra mim isso é trágico, porque dificultou trabalharmos para além dessas fronteiras. Não faz sentido, todas essas questões permeiam a mesma realidade, então eu dei um passo atrás. Algumas pessoas dizem que faço estudos culturais e respondo que não, que venho perguntando questões sobre a comunicação mas de diversos tipos. Certas perguntas requerem consideração sobre pesquisas de audiência, enquanto para outras estou interessado no que o Google está fazendo. Trata-se apenas de um tipo de análise diferente, e não uma disciplina diferente, isso não é um clube. Então me irrito, mas pra essas pessoas já é tarde demais. E ainda tem os estudantes de pós-graduação, que precisam se declarar. É como na época dos reinados, cada castelo com sua bandeira hasteada, cada um vestindo bordado o emblema do seu senhor. Isso acontece muito com estudantes de pós-graduação: "ah, sou aluno do X". Ok, mas você não tem opinião própria? Para mim a política institucional de certo modo deforma o campo acadêmico, fatiando as áreas em subáreas cada vez menores, exatamente o que se deve evitar. Neste momento da história precisamos reunir esses pedaços, mas veja o caso das revistas acadêmicas. Há uma editora no Reino Unido chamada Intellect, que é uma fábrica de periódicos. Temos o exemplo do Journal of Celebrity Studies. Alguns pesquisadores alegam que seu tema em especial é estudos de celebridade, a pesquisa sobre fama e reputação. Certamente interessante, mas um currículo inteiro dedicado a estudo de celebridades é triste, não? Notam-se esses nichos especializados cada vez mais. Há outro periódico, por exemplo, sobre estudos de big data. Sem dúvidas o big data expressa uma parte importante do que acontece no mundo digital, mas não é possível compreendê-lo por si próprio. Tudo está se tornando cada vez mais essa hiper-especialização. Ainda sou daqueles que acredita na síntese, na tentativa de reconectar as coisas e retratar um panorama maior. Então para mim é muito angustiante ver estudantes desaparecendo numa sala minúscula de departamento. Não é uma divisão no conhecimento, mas uma divisão nas instituições.

Schneider - Como o Bourdieu coloca, são disputas internas na ciência.

Murdock - Sim, as universidades sofrem do narcisismo das pequenas diferenças, então precisam construir fronteiras. Esses limites são importantes porque os recursos são limitados. Se o departamento de geografia tem tantas pessoas, talvez o de política não tenha o mesmo montante de recursos humanos, então se inicia uma batalha. Você precisa de uma economia política das universidades para entender o motivo, porque gera consequências severas na organização do conhecimento. Separam-se pessoas que trabalham até num mesmo prédio, elas nem se falam mais. Então para mim é uma corrupção institucional do conhecimento. 